people. Thus for them the "open door" often becomes a "revolving door." 3 On the other hand, they sometimes adjust surprisingly well to a therapeutic community approach in a prison unit. ${ }^{4}$ Under certain conditions, as Dr. Scott points out, prisons have therapeutic possibilities and prison officers can find such rehabilitative work stimulating and emotionally rewarding. ${ }^{4}$ Clearly, mentally abnormal offenders require treatment and not punishment but account must be taken of their ability to co-operate when deciding where they should be treated.

Obviously a range of community-based alternatives to prison are urgently needed, but it is unrealistic to expect that every abnormal offender will be suitable for treatment in community-based or in "open" hospital units or that within the foreseeable future enough community-based faciilties will be available. Thus at present many such offenders fall between two stools. They are frequently deemed unsuitable for, or unacoeptable to, "open" permissive hospital units and no adequate provision for their treatment is provided in prison. The establishment of therapeutic communities in prison should not be allowed to lead to the need for community-based rehabilitation facilities being ignored or to suitable offenders being refused admission to hospital units. The services run by the Home Office and the Department of Health and Social Security should be closely integrated -as suggested by Dr. Scott-with interested doctors and nursing staff working in both hospitals and prison. Thus, a co-ordinated long-term rehabilitation effort could often begin in a prison and be continued via a hospital unit to community services. Neither hospital nor prison treatment have a chance of lasting suocess without prolonged support in the community after discharge. But it does not help every offender if the slogan "these people need help not imprisonment" prevents the potential of prison therapeutic communities being used. A few psychopathic patients may be "carried" by a nonpsychopathic majority, but to admit all of them into, for example, alcoholic units would completely alter the therapeutic atmosphere and the (voluntary) "groupcode" and would greatly affect the morale of other patients.-I am, etc.,

M. M. Glatt

Alcoholism and Drug Dependence Unit, St. Bernard's Hoopital,

1 Glatt, M. M., Drugs, Society and Man. A Guide $o$ Addiction and its Treatment. Lancaster,

2 Rollin, H.P. ${ }^{1974 .}$., The Mentally Abnormal Offender and the Law. Oxford, Pergamon, 1969.

ournal, 1974 2, 716. M. M., British Medical fournal, 1974,
1, 56.

\section{Variations in Carboxyhaemoglobin Levels in Smokers}

SIR,-It would be valuable to be able to identify those individuals who are at high risk of developing diseases associated with smoking. Present evidence suggests that a random measurement of the blood carboxyhaemoglobin (COHb) level may be helpful in this respect, ${ }^{1}$ but since an individual's $\mathrm{COHb}$ level can fluctuate widely over 24 hours the use of a random $\mathrm{COHb}$ measure-

TABLE II-COHb Levels in Four Cigarette Smokers on Several Days

\begin{tabular}{|c|c|c|c|c|c|}
\hline \multirow{2}{*}{ Subject } & \multirow{2}{*}{$\begin{array}{l}\text { No. of Cigarettes } \\
\text { Smoked/Day }\end{array}$} & \multirow{2}{*}{$\begin{array}{l}\text { No. of } \\
\text { Test Days }\end{array}$} & \multicolumn{3}{|c|}{ Mean COHb\% (range) } \\
\hline & & & $10.00 \mathrm{hr}$ & $15.00 \mathrm{hr}$ & $22.00 \mathrm{hr}$ \\
\hline $\begin{array}{r}7 \\
8 \\
9 \\
10\end{array}$ & $\begin{array}{l}25 \\
22 \\
26 \\
20\end{array}$ & $\begin{array}{l}6 \\
5 \\
5 \\
6\end{array}$ & $\begin{array}{l}4 \cdot 8(3 \cdot 8-6 \cdot 0) \\
3.9(2 \cdot 9-5 \cdot 6) \\
5 \cdot 9(5 \cdot 3-6 \cdot 9) \\
3 \cdot 0(2 \cdot 3-4 \cdot 0)\end{array}$ & $\begin{array}{l}6 \cdot 8(5 \cdot 0-9 \cdot 1) \\
5 \cdot 0(3 \cdot 7-6 \cdot 9) \\
6 \cdot 8(4 \cdot 6-9 \cdot 2) \\
5 \cdot 3(4 \cdot 8-6 \cdot 0)\end{array}$ & $\begin{array}{l}8 \cdot 9(7 \cdot 8-10 \cdot 0) \\
6 \cdot 0(3 \cdot 8-7 \cdot 0) \\
8 \cdot 6(5 \cdot 9-13 \cdot 9) \\
6 \cdot 5(4 \cdot 7-8 \cdot 3)\end{array}$ \\
\hline
\end{tabular}

ment must be examined critically. In a recent article (28 December, p. 736) Drs.

C. M. Castleden and P. V. Cole concluded that "a random $\mathrm{COHb}$ estimation gives a good indication of the mean $\mathrm{COHb}$ of an individual," but since they do not define what is meant by "the mean COHb" and do not explain their grounds for judging how well an estimation indicated the mean, their conclusion cannot be evaluated. They claim that "in the individual smoker the $\mathrm{COHb}$ level does not increase gradually during the day but is kept within relatively narrow limits." However, their data do not support this. Some of the 10 subjects studied had $\mathrm{COHb}$ levels which did tend to rise during the day (for example, subjects $1,3,7$, and 9) and in only one was there a tendency to fall.

We have collected similar data as part of a larger study, and in our experience $\mathrm{COHb}$ levels rise during the day, usually reaching a maximum in the evening. Table I shows

TABLE I-Mean Morning and Afternoon $\mathrm{COHb}$ Levels in Six Cigarette Smokers

\begin{tabular}{|c|c|c|c|c|c|}
\hline \multirow{2}{*}{ Subject } & \multicolumn{2}{|c|}{$\begin{array}{c}\text { No. of Test } \\
\text { Days }\end{array}$} & \multicolumn{2}{|c|}{$\begin{array}{c}\text { Mean } \\
\text { COHb\% }\end{array}$} & \multirow{2}{*}{$\begin{array}{l}\text { Ratio of } \\
\text { p.m. to a.m. } \\
\text { COHb } \\
\text { Levels }\end{array}$} \\
\hline & a.m. & p.m. & a.m. & p.m. & \\
\hline $\begin{array}{l}1 \\
2 \\
3 \\
4 \\
5 \\
6\end{array}$ & $\begin{array}{l}3 \\
3 \\
3 \\
3 \\
3 \\
3\end{array}$ & $\begin{array}{l}5 \\
6 \\
5 \\
4 \\
8 \\
4\end{array}$ & $\begin{array}{l}6 \cdot 8 \\
5 \cdot 1 \\
2 \cdot 2 \\
2 \cdot 9 \\
2 \cdot 2 \\
3 \cdot 9\end{array}$ & $\begin{array}{r}14 \cdot 7 \\
8 \cdot 6 \\
5 \cdot 2 \\
6 \cdot 9 \\
4 \cdot 4 \\
5 \cdot 0\end{array}$ & $\begin{array}{l}2 \cdot 2 \\
1 \cdot 7 \\
2 \cdot 4 \\
2 \cdot 4 \\
2 \cdot 0 \\
1 \cdot 3\end{array}$ \\
\hline
\end{tabular}

the results of one series of tests in which blood samples were taken from six smokers in the morning (about 10.00) and in the afternoon (about 16.00) on several ocasions. In each subject the mean afternoon $\mathrm{COHb}$ level was higher than the mean morning level-twice as high on averageand the differences were statistically significant $(P<0.05)$. Table II shows the results of a second series in which four subjects were each tested at $10.00,15.00$, and 22.00 on at least five days, and in each subject the average of the $\mathrm{COHb}$ readings increased during each interval $(P<0.001)$. In neither of these experiments were the subjects asked to alter their smoking habits in any way, and there were no restrictions on the timing of the tests in relation to recent cigarette smoking. It therefore seems likely that a random $\mathrm{COHb}$ level corrected for the time of day provides a better indication of the mean daily level than an uncorreated random value. Indeed, a correction for recent cigarette consumption might give an even better estimate of the mean level and we have recently described a method of using a random $\mathrm{COHb}$ level in this way. ${ }^{2}$ Though such a mean COHb level is likely to be a more powerful predictor of smoking-related diseases than an uncorrected random value, this can be confirmed only in a prospective study.-We are etc.,

N. WALD SUSANNAH HOWARD
D.H.S.S. Cancer Epidemiology and Clinical Trials Unit,

Department of the Regius Professor of Medicine, Oxford

1 Wald, N., et al., British Medical fournal, 1973, 2 Wald, N., et al., Thorax. In press.

\section{Discouraging Smoking}

SIR,-Your leading article on health education (1 February, p. 233) emphasizes the failure to educate the public about cigaretteinduced diseases, and the lack of response over the past 25 years.

Successive governments have raised the tobacoo tax for the past 60 years, but this tax is now smaller owing to the present inflation. Also the cost of treating these diseases has increased out of proportion, with very little success. It is time that a sensible and realistic tax be imposed so as to reduce the amount of cigarettes bought and consumed. This revenue could help and pay for the increasing cost of the enlarging N.H.S. reorganization.-I am, etc.,

\section{A. G. I. STOCKIEY}

Thornton Heath, Surrey

SIR,-Your leading article (1 February, p. 233) on "Health Education in the Reorganized N.H.S." was most timely and, as it happens, coincided with the publication of our booklet So Now You Know About Smoking by Dr. Alfred Yarrow. Dr. Yarrow is in fact a senior medical officer concerned with the public health at the Department of Health and Social Security, so we regard it as something of a triumph to have persuaded him to write such an excellent booklet for us on this subject. Perhaps where we lead others may follow.-I am, etc.,

EvelyN BROWN Executive Editor,
Family Doctor Publications

London N.W.1

\section{Women Doctors in the N.H.S.}

SIR,-Aocording to your leading article, "State of Health" (28 December, p. 732) women form $32 \%$ of entrants to medical sohools in England and Wales yet they constitute only $11.8 \%$ of principals in general practice and $7.9 \%$ of consultants.

I work six sessions as a consultant child psychiatrist and two as a clinical assistant in a teaching hospital. My specialty is very short-staffed. I do no private practice. I spend 53 hours a week in professional activities (compared with the full-time average of 60 hours). I do some of the activities conventionally left to mothershousehold shopping, cooking, etc., and bring-
ing up children. I do these willingly, but I make the point that male colleagues generally 